\title{
The Utilitarian Argument from Risk Against Mill's Defense of Freedom of Speech
}

\author{
Zhihua Cheng $^{1}$ \& James Chambers ${ }^{1}$ \\ ${ }^{1}$ Philosophy Department, School of Politics and Law, Hebei University, Baoding, China \\ Correspondence: James Chambers, Philosophy Department, Hebei University, 71 East Street Number 2666, \\ Baoding City, Hebei Province, China. Tel: 86-152-3376-4372. E-mail: jameschambers@qq.com
}

Received: August 16, 2018

doi:10.5539/ass.v14n12p12
Accepted: September 22, 2018

Online Published: November 29, 2018

URL: https://doi.org/10.5539/ass.v14n12p12

\section{Introduction}

Utilitarianism is an ethical doctrine that prioritizes the maximization of utility in human action. Mill thinks of utility in terms of happiness. Mill defines utilitarianism in these terms: "actions are right in proportion as they tend to promote happiness, wrong as they tend to produce the reverse of happiness. By happiness is intended pleasure and the absence of pain; by unhappiness pain and the privation of pleasure." (Mill, 1861/1879, p. 60). While Mill recognizes that happiness cannot be quantified and that there are different qualities of happiness he insists that it can be measured to the extent that it is possible to compare and select acts relative to their utility. This makes it possible to act in order to maximize the most and the highest happiness for the greatest number of people involved - Mill's moral ideal. Utilitarianism is a kind of consequentialism; it claims that action can only be morally evaluated relative to its consequences. That is, no acts are right or wrong in themselves but only in terms of the extent to which they produce utility. Insofar as all sentient beings have the ability to experience utility the utilitarian attempts to take all of their perspectives equally into account.

For Mill's defense of free speech, any form of public expression, (declaring one's opinion, singing, insults) qualifies as speech. Mill regards speech as free if there are no laws against any public expression. Mill's utilitarian stance means his defense of free speech must establish that utility or, basically, human happiness, is greater in an environment of free speech than regulation.

Mill's arguments for free speech are concentrated in chapter 2 and the first paragraph of chapter 3 of his $\mathrm{On}$ Liberty. This topic has already received an enormous amount of scholarly attention much of it critical. Jonathan Wolff (2006) argues that Mill's commitment to individual rights ultimately rests upon his Victorian faith in the moral progress of western civilization and that challenging this faith has communitarian implications for utilitarianism. Robert Paul Wolff (1968) insists that utilitarianism cannot recognise the division between the public and private realms that could forbid an invasion of personal liberty. Perhaps the most uncompromising attack on the utilitarian credentials of Mill's project in On Liberty is produced by Gertrude Himmelfarb (1974) who argues that therein Mill effectively abandoned utilitarianism altogether. Isaiah Berlin (1991) is the most influential modern proponent of the view that Mill's failure to rid himself of the strictures of the crude and overbearing implications of utilitarianism hamstrung his arguments to the extent that, despite points of great complexity and depth of insight, they ultimately descended into incoherence. This is still the prevailing interpretation of Mill and so well established that John Gray and G. W. Smith (1991) call it the traditional interpretation, which Gray, Alan Ryan and John Rees attempt to challenge in different ways. This article is a novel argument for the traditional interpretation based upon problems of fallibility and risk.

\section{Mill's Arguments and the Utilitarian Case Against}

\subsection{Mill's Main Arguments for Free Speech}

Mill has two main arguments for his utilitarian defense of free speech corresponding to the truth or falsity of the views expressed:

(1) A government can suppress speech because it claims that this speech is wrong, false and harmful. Yet if there is a chance that the government's view is wrong, then by deciding to suppress the speech the argument has committed an injustice. Therefore Mill argues that a government must assume that it is somehow infallible to be justified and Mill argues that infallibility is just not possible. Think of all the beliefs once regarded as 
unquestionable truths (like the belief that the sun orbit's the earth), which are now, after scientific enquiry and debate, completely rejected by conventional wisdom. Mill argues that the government could never be certain that it did not hold such beliefs and that the views it was suppressing were not like those of the suppressed Galileo whose theories contained a progressive truth - that the earth orbits the sun for example. We have benefitted from knowing this truth.

(2) Even if the suppressed view is wholly false, by suppressing it we lose the opportunity to engage it in debate and reaffirm our own view. This is important in its own right because, Mill argues; if we do not re-evaluate our views in the light of objections then they will be held as a prejudice and not rationally. If we only know the reasons for accepting a view and none of those which can be used against it, then we do not know very much about the view. Mill argues that the consequences of this would be that the true meaning of the view is lost. Over time it is no longer understood and utility can no longer be got from it.

(1) argues that if the offensive speech contains a progressive truth then more utility is to be had from permitting it than prohibiting it because it increases our knowledge and this yields greater utility. (2) argues that if the offensive speech is false there is more utility to be had from permitting it than prohibiting it because it stimulates debate and critical thinking which sharpens our reasoning faculties and increases our knowledge of and confidence in our opinions and this yields greater utility. Mill argues that there is more utility to be had from permitting speech whether or not it is true.

Mill has a qualification of his argument which is based upon the harm principle: "That the only purpose for which power can be rightfully exercised over any member of a civilised community, against his will, is to prevent harm to others." (Mill, 1859/2001, p. 20). Speech should be prevented if it is almost certain to lead to harming others. Mill illustrates this point with the example of the 'opinion that corn-dealers are starvers of the poor.... [This m] ay justly incur punishment when delivered orally to an excited mob assembled before the house of a corn-dealer.' (p. 60).

\subsection{The Prima Facie Utilitarian Case Against and the Problem of Uncertainty}

Mill defends the right to make deeply offensive statements. Deeply offensive statements are, by definition, upsetting and as such reduce utility by their nature. On the face of it then, eliminating this kind of speech is a goal of utilitarianism. If suppressing action which is inimical to utility by force, including censorship, increases utility then it is a utilitarian duty to suppress that action. One example of offensive statements is the expression of racial hatred. Let us imagine for the sake of argument that the vast majority of a society find racist sentiments upsetting. Being exposed to racist rhetoric as preached by a minority would then decrease the overall happiness in society. If censorship of speeches expressing racial hatred could limit the depressing effects they cause society (that is if censorship could be effectively carried out), then there is a prima facie utilitarian case to make that censorship is a duty. Censorship does not violate the harm principle in this case because the unsuppressed speakers harm others by offending them.

Early in the book Mill explicitly rules out causing offense from constituting a harm. Yet later in the book he writes that some acts that are harmless in private ought to be prohibited in public because they are harmful in public. The only harm that an act permissible in private can do in public is cause offense. Therefore Mill is inconsistent in his application of the harm principle. Throughout this article it will be assumed that causing offence is a harm because utility can be Mill's only standard for assessing harm. Any other standard would require renouncing utilitarianism. Any act which reduces the utility of others must be a harm, even if it only reduces their utility in a small way. Mill denies offensive speech can be a harm because of his arguments that censorship counterfactually reduces utility more than allowing offense. This is precisely the point which is in contention here. Mill's arguments are based upon his belief in the generally predictably negative results of censorship whereas the definition of offensive speech is as a harm in itself. It is very important to qualify this point because it has already been mentioned that utilitarianism does not recognize any act as wrong in itself and I appear to be contradicting this here. Offensive speech is harmful in itself in the sense that it is defined in terms of its consequences. It $i s$ its consequences. It is speech which necessarily has offensive consequences. Without those consequences offensive speech cannot be so called. It could be said that offensive speech is not offensive in private. In this sense it is not harmful in itself. Strictly speaking this is not a misuse of the term but this is only because the term can still be used outside of its proper context when we apply a meaning of counterfactual conditionals to it. That is, we can only say for example that Paul said something offensive in private in the sense that if Peter was there, Peter could have been offended by it. Offensive speech only exists in public, or its potential to be in public, because there needs to be someone present who can be offended for it to take place. It exists only in its context or potential context. One could say that in the light of this there are two kinds of 
harmful acts: there are necessarily harmful acts like offensive speech and rape, defined in terms of their harmful consequences; and there are harmful acts like nepotism and, Mill argues, censorship, which are harmful because of the harmful consequences that tend to result from them. Mill is effectively arguing that some things, which are harmful in themselves, are not actually harmful because more harmful things come as a result of suppressing them. Suppression causes harm which outweighs the harm of offence. Mill can only argue this point by abusing the semantics of the term 'harm'. What he means is that offensive acts are merely less harmful than what comes with their suppression, not that they are not harmful at all. Something does not stop being harmful in itself merely because a counterfactual circumstance in which it is prohibited is more harmful. Anyway, these are not the only two counterfactual circumstances up for comparison. The optimal circumstances for utility for Mill would be those in which neither the act nor its suppression occurred - people simply don't want to speak racial hatred or people are so confident in utilitarian principles that they are never offended by anything, for example. These are circumstances in which the harm of offense did not occur without the negative effects of suppression. Mill could only deny that offence is a harm if he thought that the optimal circumstances, where nobody gets offended, were just as high in terms of utility as circumstances in which people were offending each other. Mill clearly denies this in his talk about private and public acts and he is right to do so. Therefore to read consistency into Mill requires the admission of offensive speech into the ranks of harmful acts.

It might be objected here that if offensive speech is judged harmful in itself in these terms then suppression is equally so. Suppression always violates the will of the ones who are suppressed and this is by its nature upsetting to them. This point can be conceded without undermining the prima facie case for suppression because utilitarianism evaluates actions in terms of utility maximization strategies. The prima facie utilitarian case for suppression of speech is consistent with the view that an offensive speech should not be suppressed in cases where it counterfactually maximizes utility by preventing a fight for example. Even though the offensive speech is a harm in such cases it is a relatively smaller harm, undermining utility less than the fight would. Similarly in the relevant case here the harm of suppression is outweighed by the harm of the offense it prevents. In the same way laws against rape prevent the gratification of the rapist but maximize the utility of potential victims. This point is open to the objection that harm of being offended is always outweighed by harm of being suppressed because being censored is very distressing. Mill couldn't make this objection because of his admission that certain public acts should be suppressed. Nevertheless, this objection raises the problems of measuring utility that are more problems of utilitarianism in general than utilitarianism in regards to free speech so they fall beyond the scope of this article. However it is worth mentioning that legal sanction is advocated by those who wish to prevent the mob violence that can ensue against offensive speakers on the grounds that noninterference on the part of legal authorities in such cases involves a greater risk of harm.

What if society is so tolerant that its citizens would rather be offended than have regulation? Although this may seem like a utilitarian argument it is not, because if people would rather be upset than lose free speech then they must regard free speech as an end in itself and for a utilitarian happiness is the only end in itself. Using (1) Mill could say that allowing the expression of racial hatred may yield some valuable truths. While it may be (and indeed should be) conceded that there is little if any truth involved in racialist dogma, allowing it to be voiced openly may help opponents of racism to develop more compelling arguments which put people off becoming racists and arm citizens with greater confidence in their own views thus contributing to greater human happiness (2).

Mill is probably right in thinking that the best environment for the development of ideas is one of open debate but Mill's argument relies on the implicit assumption that knowledge should lead to happiness. Yet knowing the truth and human happiness are different things. The philosopher Jean Jacques Rousseau famously argued that knowledge and the pursuit of it have contributed more to the misery of mankind than happiness (1971). "Almighty God! Thou who holdest in Thy hand the minds of men. deliver us from the fatal arts and sciences ... give us back ignorance, innocence, and poverty, which alone can make as happy and are precious in Thy sight' (Rousseau, 1971, p. 27). "Beneath Rousseau's rhetoric is a very serious objection to Mill's project. Can it be right to assume that it is always better to know the truth than to remain in ignorance? Mill's argument appears implicitly to assume that knowledge will lead to happiness, but why should we believe that?" (Wolff, 2006, p. 121) Relative to some frightening truths we could yet discover, the ignorance we are in could really be bliss. If Rousseau is right then on utilitarian grounds we would be justified in banning not only those speeches which upset most people now but all avenues of new knowledge. Mill replies to this argument by saying that just as we are not infallible judges of truth, we are not infallible judges of the harm an opinion may cause. Yet in order to be justified in banning a view, there "is the same need of an infallible judge of opinions to decide an opinion to be noxious as to decide it to be false." (Mill, 1859/2001, p. 30). We can predict that a speech will lead to harm and 
so ban it, but if our prediction is wrong then we have robbed society of an opportunity to increase happiness. However this reply does not argue enough in order to establish that free speech is the superior option to censorship. It is clear that it works both ways. We could just as easily allow a speech which we judge will contribute to human happiness and be mistaken - it leading to misery. So Mill's reply gives us no more reason to allow free speech than censorship. The worth of arguments (1) and (2) depends on the assumption that knowledge in general leads to greater human happiness than ignorance does. Mill's argument that we cannot know for certain what will be the outcome of permitting a speech or opinion implies that both positive and negative outcomes are possibilities. Argument (1) contradicts this in assuming that free speech is generally counterfactually positive in its outcomes whilst (2) contradicts this in arguing that censorship is counterfactually negative in its outcomes. Mill is trying to have his cake and eat it here. The consequences of free speech are either predictable or unpredictable but Mill wants them to be both; unpredictable when someone wants to ban it and predictable when someone wants to compare its merits with those of censorship. It is sophistry to argue in one place that we have no right to suppress free speech because we cannot predict whether or not it will lead to harm whilst at the same time, in a different place, assuming that free speech's consequences are predictably counterfactually positive in comparison with censorship. Perhaps coherence can be read into Mill if we use the idea that he means the general counterfactual superiority of free speech is predictable even if the consequences of particular instances of free speech cannot be predicted. An advocate of censorship does not have to make this concession from what Mill has said, Mill has not argued this, but we can make the concession anyway for the sake of further argument down this line of thought. With this in mind it is worth noting that reconstruction of Mill's opinion still concedes that sometimes the effects of free speech are harmful as well as positive and he also concedes that we are fallible in making predictions. Even if the effects of free speech or censorship can be predicted in some general way Mill can only be read consistently if he is read to admit that we are in an important sense taking a risk either way.

\section{Risk}

The problem of ignorance in predicting the consequences of free speech becomes acute for Mill when we introduce the notion of risk. Let us imagine in a thought experiment that we can overcome all the problems involved with the idea of quantifying utility with the maximum possible human happiness being ' 10 ' and the maximum possible misery ' -10 '. For the purposes of this argument I will assume the current position of an imagined society to be ' 0 '. ' 0 ' does not quite capture the current value because I do not want it to represent the situation as neither unhappy nor happy - but rather a mixture of both. It is also debateable whether the current situation is as happy as it is unhappy. To understand why this argument is rejected as irrelevant it must be made clear that the value ' 0 ' is not a description of any particular society but just a representative case. It is our start-off point against which possible futures will be measured. This imagined society may be more unhappy the other societies or even happier than it was last year but this is irrelevant for our purposes. We are not measuring its happiness against other societies or its past. We are measuring its happiness against its possible futures. Standing in position ' 0 ' this society is completely unaware of what will be the outcome of allowing free speech (like Mill argues we are). So there is an infinite range of possibilities which must seem equally likely to the society. I will introduce two extreme possibilities.

Free speech may lead to the development of ideas which place all the citizens into a state of constant ecstasy let's call this possibility ' 10 '. Yet for all society knows, it is equally likely free speech could lead to the development of ideas which make life a constant misery, which corresponds to ' -10 '. Allowing free speech is for society to take a gamble with its happiness and its very existence at stake. But it can be argued that this is an unnecessary gamble because society also has the option of regulating speech. By restricting peoples' rights to form new ideas, society can avoid this gamble and stay in position ' 0 '. It can even ban minority racist speakers that upset most people currently in this imagined society, progress to the counterfactual position of ' 1 ' and stay there.

Why should a utilitarian prefer censorship to taking a gamble if censorship can conserve the position? Because as mentioned earlier, position ' 0 ' does not represent an absence of happiness. There is some. If you are prepared to gamble with the existence of this current happiness on a toss of a coin - that if you lose will not only result in the loss of this happiness but the imposition of tenfold misery, then this suggests that you do not think much to human happiness after all.

It is a fair criticism of the argument from risk to say that it is an over-simplification. After all, if we cannot be certain of the outcome of free speech, we also cannot be certain that the prediction that regulation would maintain society's position on the scale is not also a gamble. Perhaps in regards to regulation we are damned if we do and damned if we don't. This point can be conceded and the argument from risk keep its force because, if 
so, then we are at least justified in banning those speeches which currently upset most of society in order to maximize utility now and forget the consequences as the same risk is taken whatever is done in the long-term. Remember that offensive speech is upsetting by definition and in this sense the outcome of censorship must be known. It must be known because people can only be offended by speech which, if they did not hear it (read it and so on) it could not upset them.

Mill avoids making the criticism that both free speech and regulation are a gamble because he wants to say that the consequences of regulation can be predicted in order to make his argument (2) and say that the consequences are generally negative. In order to be consistent with his view that the consequences of free speech cannot be predicted Mill could have used the criticism of over-simplification used above but he doesn't and thus faces the accusation of inconsistency. How can the outcome of regulation be predicted with more accuracy than the outcome of free speech? Perhaps worse than this is the fact even if the predictions in (2) are accurate then a utilitarian case can be made for censorship upon it based upon its relative certainty. Let us say that, prejudice, and the general intellectual frustration which comes with censorship brings society down to position ' -5 ' in utility. The gamble of free speech remains and so does the fact that the offensive speech is upsetting. Happiness in places is still possible and more unhappy possible futures are conceivable, which for all we know could occur if we gamble with free speech. So ' -5 ' has actually become the new ' 0 ' against which possible futures of censorship or free speech are to be measured again. A utilitarian should opt for a suboptimal level of utility, insofar as that outcome is known, rather than gamble with free speech when all of society's utility is the stakes when the outcome is completely unknown. This is what game theory says about the prisoner's dilemma even with lower values. In this case the stakes couldn't be higher.

\section{The Slippery Slope of the Harm Principle}

Mill claims that the outcome of free speech cannot be known. Against this he also claims that to some extent, the consequences can be predicted as qualification of the situation with the corn-dealer mentioned in the first section makes clear. The vagueness of this qualification amounts to another argument for regulation. If the calls for attacking the corn-dealers do not in fact lead to violence then punishing the orators seems an injustice because of Mill's arguments in (1) and (2). Even if it does result in violence, (1) and (2) could still be used to argue that in the longer run the speech may result in greater utility than otherwise. There is no limit to the time frame for assessing the risk of allowing free speech. As we can stretch the timeline of the causal chain of the consequences of actions needed for evaluating them on ad infinitum the utility of any act cannot be evaluated without a purely arbitrary timeframe of evaluation. Mill argues that maybe, despite its immediate offense, somewhere down the line in our future offensive speech might contribute to an increase in utility, greater than we would have had, had the speech been suppressed. But by the same token, had the government allowed the threatening speech against the corn-dealer, had the government allowed violence against him that could ensue, somewhere in the future this could also have counterfactually increased utility - maybe the corn-dealer would have become the next Jack the Ripper. It is unknowable. Yet Mill does not accept this here. He seems to think against his own reasoning about the unpredictability of the outcome of free speech. He judges that we are justified in intervening when we judge that a speech will lead to violence even though we aren't infallible.

This view is the first step on a slippery slope. It is not merely that the government is justified in intervening when it judges that a speech will lead to violence even though it is not infallible; it is more like a government seems justified in banning speeches precisely because it is not infallible. After all, how direct an appeal to harm others is, is a matter of opinion. In the heat of the moment corn-dealer case there isn't even time to rationally weigh up the probabilities. This implies that even poor predictions of harm are justified. Mill argues that we cannot make an infallible prediction of the outcome of free speech. If the government can be justified in banning speech even though it in fact will not lead to harm because the government believes it will, then Mill seems to concede all to regulation.

\section{Conclusion}

It seems that in utilitarian terms, we are justified in regulating speech even if it is true or will lead to discoveries of the truth because knowledge and happiness may conflict. We are also justified in regulation if we have no idea what will be the consequences of free speech and/or regulation because it is not worth risking the future happiness of society for free speech and regulation can eliminate some immediate woes of society being offended by minorities whilst taking the same long term risk. We are also justified in regulation even though we can predict that regulation reduces utility because those consequences are still counterfactually better than other possibilities that cannot be predicted. Also, if we are justified in regulation when we predict harm we are justified even if this prediction is wrong. 
Mill was very keen to justify individual rights in the face of 'tyranny of the majority'. This essay has contributed to the argument that this cannot be done in utilitarian terms. It is not however, a complete refutation. The utilitarian could still offer other options for silencing the upsetting minority with more positive side effects than censorship like progressive education, social activism, peer pressure and media campaigns for instance. In those cases Mill could argue that those options offer greater utility than either merely suppressing the speech or allowing it. This article has not addressed itself to those alternatives because they are wrapped up with questions of the practicality of application - the question of whether or not they can be applied more effectively than suppression. They do not strictly concern themselves with the rightness or wrongness of the principle of suppression as such but its relative merits in eliminating offensive speech from the public realm. Mill argues that suppression is always wrong, not because there are more favourable options but because it is always bad. Mill does not argue censorship is the second best option. He argues that it is wrong. I repeat here the point of contention of this article that I italicized in section 2.2: If suppressing action which is inimical to utility by force, including censorship, increases utility then it is a utilitarian duty to suppress that action. The article has addressed itself to the argument to be made for this claim from risk. This article is addressing the controversy of this 'if': It has argued that if free speech can be suppressed by force then it should be on utilitarian grounds because of problems of risk. Mill has other arguments against suppression in On Liberty to the effect that it is impracticable. These arguments are not strictly concerned with the utility of the suppression of free speech but its feasibility. I have not addressed the question of whether or not censorship can be effectively carried out (questions of alternative programs are relevant here). Rather, I have merely addressed the question of if suppression is feasible whether or not the utilitarian should support it in principle. I have argued that Mill's spirited arguments against the utility of suppression fall foul of the problem of risk. None of this implies that there is anything wrong with the principle of free speech. It merely implies that if there is a case to be made for the principle of free speech then utilitarianism has proven, in Mill's failed arguments, to be the wrong moral theory to use to make that case.

\section{References}

Berlin, I. (1991). John Stuart Mill and the Ends of Life. In J. Gray, \& G. W. Smith (Eds.), J. S. Mill on Liberty in Focus (pp. 131-162). London: Routledge.

Gray, J. (1991). Mill's Conception of Happiness and the Theory of Individuality. In J. Gray, \& G. W. Smith (Eds.), J. S. Mill on Liberty in Focus (pp. 190-212). London: Routledge.

Himmelfarb, G. (1974). On Liberty and Liberalism: the case of John Stuart Mill. New York: Knopf.

Mill, J. S. (1861/1879). Utilitarianism (reprinted from Fraser's Magazine, 7th ed.). London: Longman's Green and Co.

Mill, J. S. On Liberty (1859/2001). London: The Walter Scott Publishing Co., Ltd.

Rees, J. C. (1991). A Re-reading of Mill on Liberty. In J. Gray, \& G. W. Smith (Eds.), J. S. Mill on Liberty in Focus (pp. 169-190). London: Routledge.

Rousseau, J. J. (1973). The Social Contract and Discourses. G. D. H. Cole, J. H. Brumfitt, \& J. C. Hall (Eds.). London: Everyman.

Ryan, A. (1991). John Stuart Mill's Art of Living. In J. Gray, \& G. W. Smith (Eds.), J. S. Mill on Liberty in Focus (pp. 162-169). London: Routledge.

Wolff, J. (2006). An Introduction to Political Philosophy. Oxford: Oxford University Press.

Wolff, R. P. (1968). The Poverty of Liberalism. Boston, Mass: Beacon Press.

\section{Copyrights}

Copyright for this article is retained by the author(s), with first publication rights granted to the journal.

This is an open-access article distributed under the terms and conditions of the Creative Commons Attribution license (http://creativecommons.org/licenses/by/4.0/). 